\title{
Editorial
}

\section{Physics and (Natural) Philosophy}

Langdon's Winner landmark essay in the philosophy of technology, "Do Artifacts Have Politics?," suggested that the argument that technologies are political is one of the most radical and contentious claims we can make about technology. We might say the same thing about theories. The notion that they are political, philosophical, or ideological is bound to ruffle feathers. Scientists and historians of science today often assume that when physics is explicitly philosophical, or representative of a worldview, that this is a problem. Is it?

That question came up during the 150th anniversary of the iconic scientific journal Nature. The journal celebrated its sesquicentennial by publishing a series of articles discussing a century and a half of its history, including some episodes that show the journal in a critical light. These articles included one by John Hopkins University historian Nathanial Comfort that discussed the journal's nowdisturbing role as an early disseminator of eugenic thinking. Comfort's point was a simple one: science, like other human endeavors, is inevitably of its time and we should not rely on science alone to tell us what it means to be human.

Some found this upsetting. Describing it as an "antiscientism rant," for example, the Harvard University cognitive scientist Steven Pinker complained on Twitter that Comfort and historians of science more generally "hate [science's] claim to objectivity and reason." Any objection to-or even nuancing of-that claim, according to Pinker and others, must be anti-science. But any careful consideration of science's history reveals how strange it is to suggest that the goal of reason is at odds with a vision of science as responsive to the social, political, and philosophical settings in which it unfolds.

As Melinda Baldwin documents in her authoritative history of Nature-Making "Nature"-almost none of its contributors would have self-identified with the word "scientist" when it debuted in 1869. Nature's authors were "men of science" or "natural philosophers." As the latter term in particular highlights, the systematic study of the natural world remained firmly a philosophical enterprise through the years that produced some of our most enduring scientific developments. Moreover, many natural philosophers took considerable pride in the appellation, and blanched at the suggestion that they should abandon it in favor of a term like "scientist," with its overtones of vocationalism and narrow specialization.

Since then, the language of philosophy has fallen out of favor in the sciences, and especially among physicists. In part, this is a hangover of the so-called Science 
Wars of the late twentieth century, which caused many physicists to bristle at what they perceived as an unwarranted attack on the authority of their knowledge. Philosophy, in this conflict, became a codeword applied to the perceived political enemies of science, and that understanding continues to inform attacks on philosophy as the enemy of reason. But this is a narrow and counterproductive way to understand the relationship between science and philosophy.

Helge Kragh's 2019 Pais Prize lecture, printed as an article in this issue, discusses one way in which philosophical concerns have been a guiding light of physical inquiry. Kragh addresses the history of speculation about whether the constants of nature actually are constant. We might not now put much stock in the idea that physical constants might have changed over the sweep of the universe's history, but the very question is one that inspired physicists to question the foundations of their practice, and thereby pushed the field forward.

Physicists, that is, never stopped being philosophers when they stopped calling themselves philosophers. They might well be proud to wear the label again.

Robert P. Crease

Joseph D. Martin

Richard Staley

Publisher's Note Springer Nature remains neutral with regard to jurisdictional claims in published maps and institutional affiliations. 